\title{
Literacy practices in Schome Park: a virtual literacy ethnography
}

\author{
Julia Gillen
}

Lancaster University, UK

\begin{abstract}
In this paper I deploy a synthesis of methods I term virtual literacy ethnography to investigate the diverse literacy practices of the project Schome Park. Participants have been engaging over a 15-month period in an innovative out-of-school project centred on use of the (Teen) Second Life three-dimensional virtual world. Some ethical aspects of working with children in virtual worlds are briefly discussed. I analyse evidence from the three main communicative domains of the project: chat logs, wiki and forum, demonstrating the complexity and creativity of student literacy practices. I include in my data selection exemplars that draw on persistently valued literacy texts and demonstrate that attentive examination to literacy practices may be more fruitful than maintaining overly dichotomised boundaries between new literacies and those more established.
\end{abstract}

In this paper I aim to explore the range of literacy practices taking place in Schome Park, a three-dimensional (3D) virtual island world, during a 15-month period (February 2007May 2008). My second aim, entwined with the first, is to develop in practice an appropriate methodology. I shall endeavour to demonstrate that new literacy practices are best approached by a new synthesis of methods, recognising distinctions between new literacy practices as understood mostly, but not wholly, in connection with the opportunities offered by digital technologies and the methodological paradigms with which their study is associated. I term my approach virtual literacy ethnography.

Taking a broadly ethnographic perspective from the outset, a descriptive introduction to the settings and activities under investigation cannot be disassociated from a consciousness of my own, constantly shifting, involvements in the events and practices. This paper is exploratory in that I seek to set out a potential trajectory for analysing some dimensions of these contexts that are novel in terms of new blends of semiotic resources, overlapping sets of purposes by those involved and particular aspects of identity that are shaped and reshaped as learning takes place. I include in my data selection exemplars of playful work that draw on recognisably persistent and valued genres re-contextualised to new channels. This is in part with the aim of building bridges to those interested in literacy education who have not yet engaged with cutting-edge technology innovations and perhaps do not yet see any need to do so. Not because I want to add to the social pressures to jump on the latest innovations that so bombard educationalists of every type but because I wish to challenge the highly dichotomised media discourses that sometimes characterise writings about children in virtual worlds. To take one example, the BBC 
journalist John Humphrys, writing in the Daily Mail, posed the following questions under a subheading " Virtual reality" websites - a disturbing world stripped of humanity and moral values':

What the hell is it? What's the point of it apart from allowing a few people with nothing better to do to play out their fantasies? And above all, if it is really going to change anything, at what point does fantasy merge into reality? The answer to that last question is that it is already happening and with potentially disturbing results (Daily Mail, 5 January 2008, p. 40).

I will present evidence to suggest that more constructive questions to ask of the environment might include: what is new here? What is going on in terms of literacy practices and indeed development of skills? How do certain new technologies provide specific new opportunities, if they do and how worthwhile are these, including from the perspectives of those engaged? I want to present a truly introductory paper in the sense that I endeavour too, in an anthropological spirit to 'make strange' the already familiar to those engaged in new technologies too, not least in specifically examining the potentials of methods for their study. Uncertainties around the appropriateness of existing research methods to new combinations of communications technology can be productive (Hine, 2000).

First, then, I will outline features of the project that need describing in order to enable situated understanding of its literacy practices, including brief adumbration of my own involvement. Second, I will trace parts of the route that I take in forming a methodology for investigation, including some attention to ethical issues in virtual research with children. Third, I will seek to present some analyses of literacy practices.

\section{The Schome project and Schome Park}

In February 2007 I joined the Schome project shortly after it opened its first island for teenagers on the Teen Second Life sector of the 3D virtual world Second Life. ${ }^{1}$ The project ran in three phases between February 2007 and May 2008 with some pauses for technical changes, especially building developments and expansions of the island/s as well as new waves of participant recruitment. Some communicative domains of the project including the forum and wiki, as will be described, ran throughout.

The Schome community, led by Peter Twining of the Open University, was already active as an essentially voluntary organisation under university auspices comprising a wide range of people interested in what might loosely be termed alternative models of education. Including academics, parents, young people, policy-makers, educators and other interested parties, the Schome Community was established with the aim of creating 'a new form of educational system designed to overcome the problems associated with current education systems in order to meet the needs of society and individuals in the $21 \mathrm{st}$ century' (Sheehy, Ferguson \& Clough, 2009). This virtual community has sought and engaged with a wide variety of perspectives on educational practices and potential educational futures, consistently enacting a view that genuine participation by learners must be instantiated at all stages of planning and operationalising education. (It is beyond the scope of this paper to participate in the ongoing scholarly discussions of how precisely to define a 'virtual community'; although see Barab, Kling and Gray [2004] for 
a helpful outline of relevant approaches.) Within the Schome Community technology is seen not only as a tool to support and extend existing practices but also as having the potential to transform ways of representing the world and of supporting learning. Sharing this perspective, with particular interest in new literacies (Tusting, 2008), I was attracted by the Schome Community's decision to explore the potential of virtual worlds, considering their capacity to act as spaces in which visions of future practices and pedagogies can be built and experienced, making it 'possible to construct, investigate and interrogate hypothetical worlds' (Squire, 2006, p. 19).

Second Life is split into two distinct and mutually inaccessible areas. Second Life is designed for adults aged 18 and over, while Teen Second Life is restricted to young people aged between 13 and 17 and credentialised adults. The first phase of the virtual worlds project, the Schome-NAGTY Teen Second Life Pilot, was the first European enclosed island. In October 2006, supported with funding from National Endowment for Science Technology and the Arts, the Schome Community purchased an island in Teen Second Life called Schome Park. Schome Park was the first European enclosed island on Teen Second Life. 'Enclosed' here means that use is restricted to children invited to join the project, usually via their schools, with the written informed consent of their parents and schools as well as themselves, plus adult staff members of the project who are individually recruited and have had their credentials checked through the Criminal Records Bureau (enhanced disclosure) or equivalent for foreign nationals. Avatars once joined cannot leave the island and visit other areas of Teen Second Life or of course Second Life. The adult arena Second Life has received considerable negative media attention, including with regard to its burgeoning actual economy and its enormously diverse range of activities, including gambling (now banned) and sexual simulations; Guest (2007) provides a lengthy account of exploitative activities detrimental to the mental health of some vulnerable adults.

As an ethical educational project with funding including from The Aspire Pilot, National Association for Gifted and Talented Youth and Becta during its three phases (to date), the Schome Community is rightly vigilant to ensure that participation in the project is restricted to credentialised individuals, both students and staff, and that conduct is appropriately overseen. Anonymity of the students is preserved within the project although a securely held database with real contact details is held by a few members of core staff in the event that any concern should be raised on-line as to a 'real world' emergency necessitating contact with an actual individual and his/her parents/ guardians. To my knowledge such an emergency has only occurred a few times, for example when one volatile individual claimed he was seriously ill and alone. The project director phoned his parents and found fortunately that this was not the case. I have had access to the database during much of the project, but have never had to use it and therefore do not know the students outside their pseudonyms, avatar representations and writings. (On fewer than a handful of visits I have heard a tiny amount of speech in-world.)

My identity then is that of a member of staff with certain responsibilities and commensurate powers but that characterisation in no way conveys the identity I feel I perform (Goffman, 1959) in the environment. For there I, through my avatar, Rowan, am indeed a researcher taking a lively interest in many aspects of the project but, as an equally strong if not stronger aspect of my identity, a learner. A slow learner, indeed, who in a very high proportion of interactions with students especially, is learning new skills and knowledge, while endeavouring at the same time to record and reflect. 


\section{Schome Park's three main domains of communication}

Over the 15 months members of the Schome Park community have interacted in three main communicative domains, as even when the island/s are closed for respite/ redevelopment communication continues via two associated domains: a forum multiply threaded for asynchronous discussions and a wiki, compilation of individually authored web pages that can be edited by other project members. (There are other project communication tools such as blogs, dynamic profiles etc. not discussed here.) At this point it will be useful to explain with illustrations in terms of literacy affordances these three main communicative domains.

\section{Schome Park island/s}

Figure 1 is a screenshot, i.e. copy of my PC screen, taken to show some features of a typical view such as I see when 'in-world' to use the prevailing word describing immersion into the environment. I have reproduced this screenshot in order to establish the complexity of reading and writing demands of the environment, even before interaction with others is considered. It is immediately important to note that this image is already very falsified, being black and white rather than full colour; many of the tones have been flattened, and the sounds have been removed. I am not going to describe all the functionality hidden behind the tabs that surround the scene; these can best be

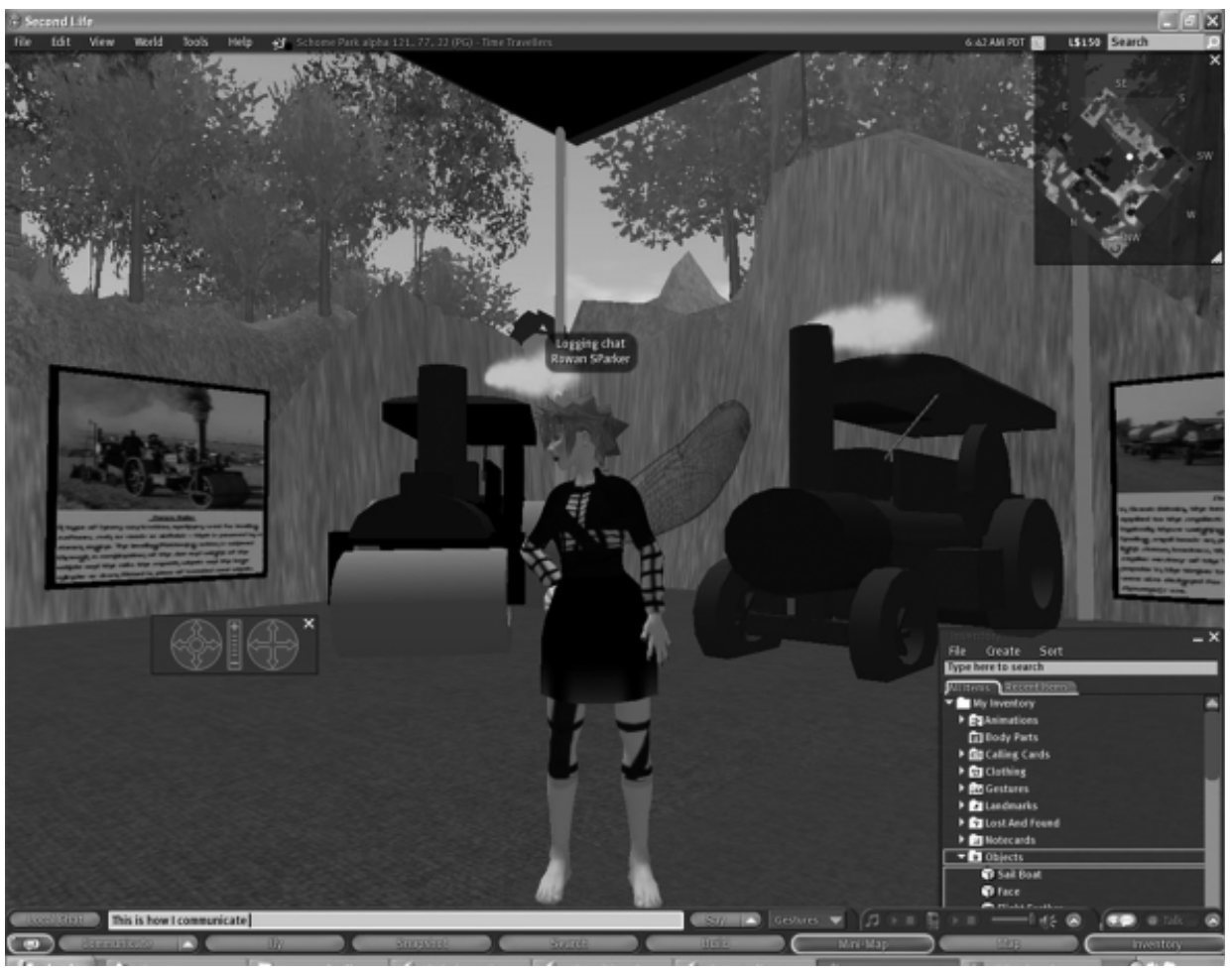

Figure 1. Rowan the avatar in Schome Park, 13 April 2008. 
encountered through learning to use Second Life and/or reading a popular guide. But it should be noted that these have menus and submenus and thus entail considerable reading work, not least in deciding what is relevant or might be helpful at any given time. Engaging with (Teen) Second Life is a literacy activity, as are massively multiplayer on-line games (Steinkuehler, 2007). At the centre of the image is the avatar through which I am represented in-world, Rowan. She is currently a punky looking fairly young woman with blue hair and wings but during the phases has had quite different appearances, for example a balding man in a lab coat, a young black man modelled on the footballer Emanuel Adebayor and a dowdy middle-aged woman. (Teen) Second Life gives the illusion of 3D space; Rowan can move around by walking, flying or running. It is often more useful to engage with the world through the avatar's eyes, but in order to present the avatar in the image for this purpose I have utilised the 'camera controls' which are the two superimposed wheels towards the bottom left. Rowan is standing in a corner of the steam museum which has been built very recently and which is about to be associated with a 'murder mystery' event. Environmental print features commonly; here posters on the wall show photographic images of the 'real' steam engines and given historical information about them. A student has made the two artificial steam engines visible as 3D objects in-world; one emits authentic steaming sounds. At the top right of the image I have opened a map that indicates where my avatar is located on the island and where others are. At the bottom right I have opened my inventory which includes note cards - written texts that I have been given and decided to keep about events, instructions and so forth. They are authored by other community members. At the bottom left is an open white box with text inside; this is the main 'chat window' through which I can communicate synchronously with anybody close enough. I can also open up a further box for private conversations and for leaving messages for those not in-world at present. There are many links in-world to web pages and the other communication tools of the project.

This image has been kept simple in that Rowan is alone; if there were another avatar present and visible, the whole scene would appear to the second person from their avatar's/camera's perspective and their screen would also differ according to which tools and functionalities they were dealing with at that particular moment. So the screens we would be reading would look very different, even if we were interacting together. Here we see 'radically changing forms and functions of texts, which go beyond traditional conceptions of what literacy is and has been' (Kress, 2005, p. 1). 'New literacies' are increasingly multi-modal: 'meaning and knowledge are built up through various modalities (images, texts, symbols, interactions, abstract design, sound etc.) not just words' (Gee, 2003, p. 210).

As a researcher, Rowan displays a message saying 'logging chat' above her head, combating 'the illusion of privacy in cyberspace' (Frankel \& Siang, 1999). I intend to remind Rowan's interactants that at all times she is preserving written records of any interactions she is involved with, or reads in her immediate vicinity. Avatars present in her environment may have private conversations through the messaging system she is not privy to, and all communications made when staff are not present, that is the majority, are not recorded.

In order to present a glimpse of in-world interaction, Table 1 shows an extract from a chat log preserved from 22 January 2008. This data record is extremely impoverished in comparison with the original interaction situated in the $3 \mathrm{D}$ virtual environment, presented uniquely according to the vantage point and combination of potential semiotic resources 
Table 1. Extract from chat log, 21 January 2008.

1. [2008/01/22 10:59] baso Schomer: hey

2. [2008/01/22 10:59] You: hi baso

3. [2008/01/22 10:59] You: how are things?

4. [2008/01/22 11:00] Object: baso Schomer this option isnt finished just yet, please conact Baso 'spb'.

5. [2008/01/22 11:00] SPbTP whispers: Destination data loaded. Transporter is ready.

6. [2008/01/22 11:00] baso Schomer: good

7. [2008/01/22 11:00] baso Schomer: just set up the teleport network for everyone

8. [2008/01/22 11:00] baso Schomer: to help the get round

9. [2008/01/22 11:00] You: would it be possible for me to have a copy of the schome logo you have on your tee shirt

10. [2008/01/22 11:00] baso Schomer: i didnt make it

11. [2008/01/22 11:00] You: I thought it was you as I heard the star trek fizzing noise I like

12. [2008/01/22 11:00] baso Schomer: otherwise sure

13. [2008/01/22 11:00] baso Schomer: :P

14. [2008/01/22 11:01] baso Schomer: wel i configured it to be a cross between stargate and startrek now :D

15. [2008/01/22 11:01] baso Schomer: the beam is so last century :p

16. [2008/01/22 11:01] You: OK fine though I never could get on with stargate

17. [2008/01/22 11:01] baso Schomer: wear that

18. [2008/01/22 11:01] baso Schomer: wel its sort of a portal

19. [2008/01/22 11:01] You: yes it's funny how scifi dates!

20. [2008/01/22 11:01] baso Schomer: that you click

21. [2008/01/22 11:01] baso Schomer gave you SPTC iHUD.

22. [2008/01/22 11:01] baso Schomer: ok ... im off to some remote location ot eat my dinner

23. [2008/01/22 11:01] You: thanks

24. [2008/01/22 11:01] Object: baso Schomer this option isnt finished just yet, please conact Baso 'spb'.

25. [2008/01/22 11:01] SPbTP whispers: Destination data loaded. Transporter is ready.

26. [2008/01/22 11:01] SPbTP whispers: Destination data loaded. Transporter is ready.

27. [2008/01/22 11:02] baso Schomer: ok

28. [2008/01/22 11:02] marsbar9 Schomer is Online

29. [2008/01/22 11:02] baso Schomer: i need to reconsifiger mine

30. [2008/01/22 11:02] baso Schomer: go ahead

31. [2008/01/22 11:02] baso Schomer: take the teleporter out for a spin ... btw the compass is the teleport rezzer :D

32. [2008/01/22 11:02] baso Schomer: enjoy the iHUD

33. [2008/01/22 11:02] SPbTP whispers: You are not authorized to use this teleporter.

34. [2008/01/22 11:02] Animus Schomer: hey

35. [2008/01/22 11:02] Animus Schomer: baso

36. [2008/01/22 11:02] baso Schomer:/afk

37. [2008/01/22 11:02] Animus Schomer: could you add me as an sptc manager?

38. [2008/01/22 11:02] SPbTP whispers: Transporter destinations:

39. [2008/01/22 11:02] SPbTP whispers: Sandbox+Maze: $\langle 61,177,41\rangle$

40. [2008/01/22 11:02] SPbTP whispers: Lyceum: $\langle 141,214,48\rangle$

41. [2008/01/22 11:02] SPbTP whispers: Jap Garden: $\langle 123,124,22\rangle$

42. [2008/01/22 11:02] SPbTP whispers: Caves-Room: $\langle 136,164,25\rangle$

43. [2008/01/22 11:02] SPbTP whispers: Caves-Entrance: $\langle 87,170,41\rangle$

44. [2008/01/22 11:02] SPbTP whispers: SchomeCentral: $\langle 138,163,40\rangle$

45. [2008/01/22 11:02] SPbTP whispers: Entrance(in SPb): $\langle 137,36,49\rangle$

46. [2008/01/22 11:02] SPbTP whispers: Entrance(in SPa): $\langle 137,16,49\rangle$

47. [2008/01/22 11:02] SPbTP whispers: :

48. [2008/01/22 11:02] SPbTP whispers: :

49. [2008/01/22 11:02] SPbTP whispers: Total destinations $=10$

50. [2008/01/22 11:02] SPbTP whispers: Initializing pattern buffer.

51. [2008/01/22 11:02] SPbTP whispers: Energizing transport beam.

52. [2008/01/22 11:03] SPbTP whispers: Squishing Rowan SParker into ball.

53. [2008/01/22 11:03] SPbTP whispers: Transporting ...

54. [2008/01/22 11:03] SPbTP whispers: Unsquishing Rowan SParker.

Note. The line numberings have been inserted subsequently by the author for ease of reference and do not appear on the original logs. 
utilised at the time by each participant. Nevertheless it is useful in preserving the written text that has appeared in my chat window.

I have selected this extract as in some senses relatively accessible to the reader. It contains canonical conversational features such as openings and greetings (Sacks, Schegloff \& Jefferson, 1974), one distinct narrative and fewer interactants than many logs of such multiparty events as meetings and other large social gatherings.

My field notes bolster my recollection of these events 6 months later. To select the most salient aspect of these from my point of view: Beta island had recently opened for the third phase of the project; in exploring I met baso who several times during the project assisted in my learning about the environment and how to explore it.

A brief explanation of some features may assist reading the chat log.

- It is organised by turn, each timed by the information provided within the initial square brackets; overlaps are effectively disguised because turns are always organised sequentially even though in practice sometimes a writer might be in a turn responding to an earlier turn than that which appears in the log immediately above that entry.

- After the time entry is an identification of the speaker or rather producer of the turn; in this transcript 'You' is Rowan SParker; students are identified as '(name) Schomer'; and all other entries are scripts, that is automated turns produced by in-world objects (that have been programmed to do this, in the instances evident here by students).

\section{Asynchronous forum}

The Schome Park forum is the most constantly used means of communication in the project. Access to it is simpler and quicker than going in-world because it can be accessed through any Internet browser. Areas of the site are accessible to the public (for general discussions about education, introductions to Schome, etc.) but most of the site is accessed by members through logging on. Postings are persistent, although some threads are archived periodically, and the forum is monitored by staff.

Frequently, the forum is used to collaboratively plan events, discuss happenings within the project, its interactions with the wider world and so on. There are also self-contained forum games and discussions on diverse topics such as archaeology, video production, consciousness and school dinners (to mention just a few of the topics I have been involved with). Some topics are related to the community life of Schome Park, yet without any intention to directly link to in-world events. Figure 2 shows such a posting by a student, who initiated a new 'thread' (topic; subset of the forum). It was responded to by a staff member (and forum moderator) 4 minutes later and then after about half an hour by another student. I was wholly uninvolved in this forum, failing to notice it in the stream of communications. I turn to it now as, in contrast to Table 1, it evidences use of a more inter-generationally valued literacy genre, the dictionary.

\section{Wiki}

Almost exactly 24 hours after the first posting, both Trixxiee the originator and another student, Marsbar9, started simultaneously creating and authoring a new page on the wiki where the dictionary could reside. Figure 3 shows an initial wiki page as it stood, after 


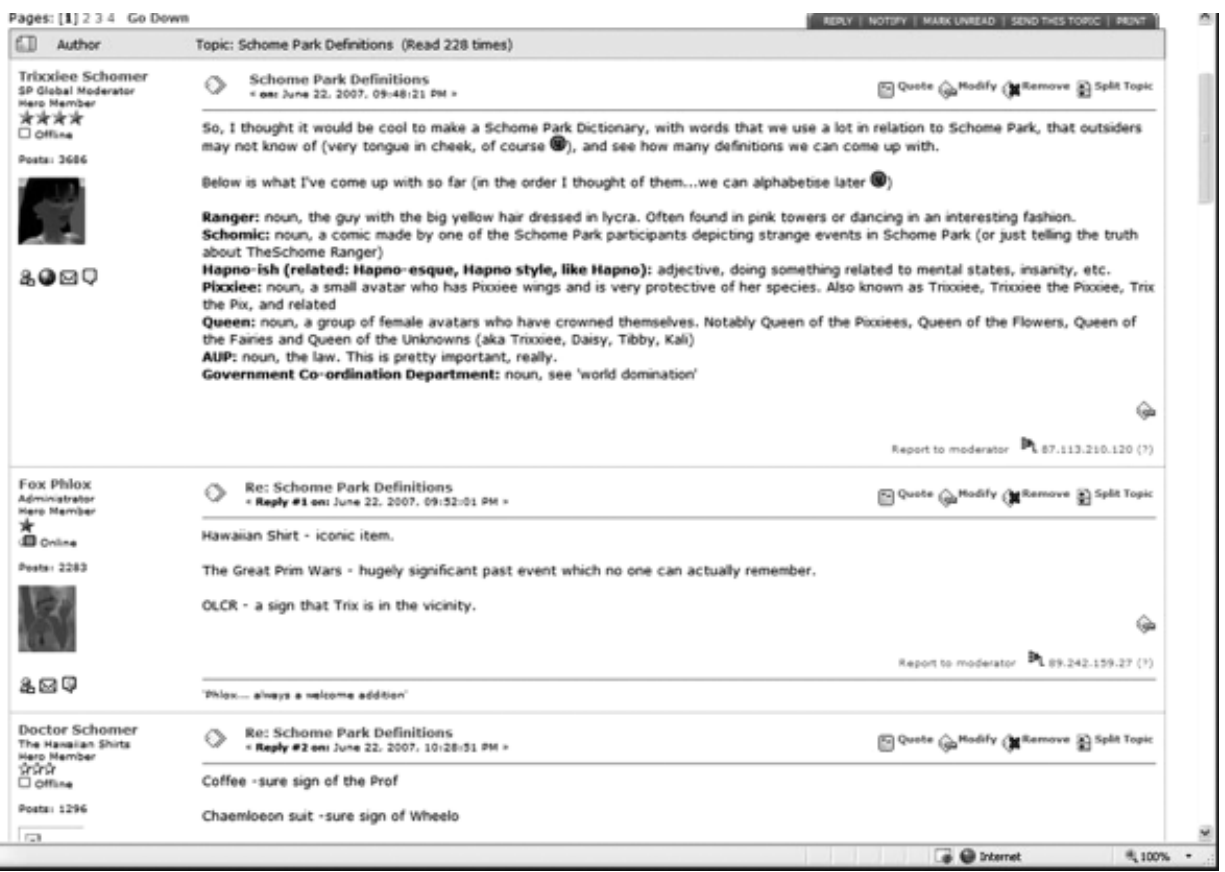

Figure 2. A thread on the Schome Park forum, from 22 June 2007.

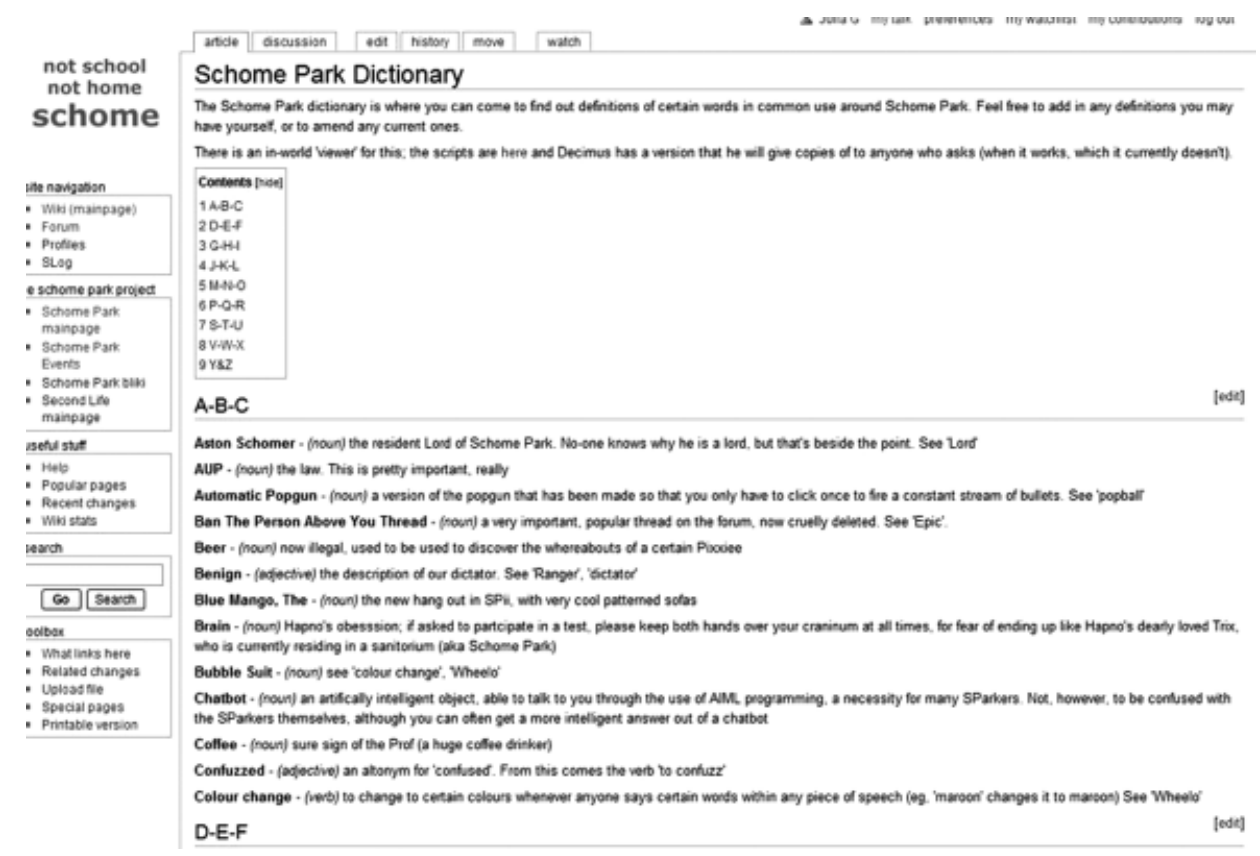

Figure 3. An excerpt from a wiki page, captured 20 February 2008. 
considerable collaborative activity, as captured several months later. I will return to some analysis of the central content of this page below but here point out central aspects of functional design.

This and every wiki page of the project can be divided into two distinct areas. The top and left hand areas of the page are (for most users) relatively fixed; indicative of available menus, automatic and generalised design features across the wiki. Without entering into overly detailed discussion: the top right list relates to personalisable filters, as well as logging in and out. The tabs at the top left allow various functions, for example if you click 'edit' at the top, and you are a member of the project, you will have the opportunity to edit any part of this page, preview your amendment and then save it so that anyone visiting the web page will see the new version. The left-hand border of the page gives navigational choices and a search facility; those who get involved with designing the overall wiki structure make design choices here but most wiki users develop their own pathways through these.

\section{Towards virtual literacy ethnography}

Following from this descriptive introduction to the literacy practices of Schome Park I intend to sketch out why 'virtual literacy ethnography' may be an appropriate term to delineate the mixed methods I employ to study these and related phenomena.

As briefly mentioned in the introduction, it is probably useful to characterise a notion of 'new literacy practices' or 'new literacies' as a concept mostly but not entirely mappable onto contemporary digital technologies and the methodologies with which these are studied. As Lankshear and Knobel (2006) discuss, contemporary digital technologies are associated with new blends of semiotic resources, especially presented on-line. But what is crucial about the so-called 'post-typographic' era is not only affordances of digital technologies, but associated new opportunities for collaborative meaning-making, rapid dialogues in diverse formats and potentialities for communicating across what previously might have acted as obstacles to access, such as those related to time, space and aspects of embodiment including dis/abilities in the real world. Concepts such as Web 2.0 and digital literacy capture aspects of these relationships between social practices and involved technologies (see Anderson, 2007; Merchant, 2007, for pertinent overviews.) Lankshear and Knobel (2006) put their theoretical emphasis above all on the practices involved - and therefore bring into their understandings of new literacies certain practices that are not centrally focused on the use of new technologies such as print format manga comics, scenario building in institutions and sophisticated card games like Pokemon and Yu-Gi-Oh (Lankshear \& Knobel, 2006, pp. 22-27).

For those of us centrally interested in literacy studies, this sensitivity dovetails well with the perspective known as New Literacy Studies (NLS) that has developed since the 1980s (e.g. Barton, 2007; Barton \& Hamilton, 1998; Gee, 1996; Heath, 1983; Papen, 2007; Street, 1984). NLS remains relevant as a springboard to understandings of literacy in its focus on the situated character of functions of literacy, recognising the diverse purposes and understandings with which people deploy their own blends of skills in the production and uses of texts. Literacy skills then are not best understood as an abstract concept but always as related to how situations are inhabited by people who act in ways shaped by a myriad constellation of factors including their previous experiences, access to social and cultural resources, etc. Gee's (1996, p. 128) concept of discourses as 'ways 
of displaying (through words, actions, values, and beliefs) membership in a particular social group or social network [by] people who associate with each other around a common set of interests, goals, and activities' has been useful in capturing the ways in which literacies then are associated with other aspects of 'ways of being' (ibid.) and will be drawn upon again below.

Any characterisation of a 'school of thought' such as is communicated through the label NLS is at risk of oversimplifying the rich diversity of work that is imbued with strands of thinking from different disciplines; however 'ethnographic' characterises a certain commonality of interest in capturing the manifold dimensions of (new) literacy practices relevant to my interests here. By ethnographic I mean to signal a commitment to use mixed methods to endeavour to explore the research participants' own perspectives on events, to recognise the complexity of influences on practices and events and to seek to reflexively consider the researcher's development of interpretive understandings. The concept of ethnography has moved away from its original social anthropological characterisation as being associated with endeavours to follow its human subjects through every aspect of their existence, recognising that this was actually always limited in some way. So for example the ethnography of education analyses the everyday life of the classroom seeking to interpet its culture, or how people make meanings, using participant observation and interviews as key methods (Anderson-Levitt, 2006).

Virtual ethnography or cyber-ethnographies are clearly a comparable development, through which researchers use interpretive methods to explore the dynamic culture of online communities or virtual worlds (e.g. Carter, 2005; Crowe \& Bradford, 2006; Hine, 2000; Thomas, 2007). Naturally, the particular aspects of culture most sensitively explored by researchers reflect their particular disciplinary backgrounds, so in the examples just cited emphases lie on social science methodology; geographies of virtual environments; social relations; and identity, respectively.

How to think about the boundaries between virtual environments and other aspects of 'ways of being' (e.g. as captured in the extreme dichotomised term of 'real life' or 'RL') is an essential element here. For me, Hutchins (1995) in his delineation of cognitive ethnography provides a useful inspiration when he points to the deeply cultural, thus in a sense 'artificial', nature of our everyday environments and even more significantly our ways of interacting with our environment:

The environments of human thinking are not 'natural' environments. They are artificial through and through. Humans create their cognitive powers by creating the environments in which they exercise their powers. At present, so few of us have taken the time to study these environments seriously as organizers of cognitive activity that we have little sense of their role in the construction of thought (Hutchins, 1995, p. 169).

Our environments then are composed of artefacts that we perceive through culturally informed lenses; this is true of every literacy-related event whether off-line or on-line. So, although we may decide to study a virtual environment such as Schome Park, we might not necessarily locate a hard-and-fast boundary between Second Life and RL and Julia Gillen the person and Rowan the avatar but rather perceive such boundaries to be liminal and rather more subtle and interesting than binary dichotomies.

Steinkuehler (2006, 2007), for example, has applied Hutchins' notion of cognitive ethnography to a massively multiplayer on-line game (MMOG, i.e. a virtual world 
sharing many characteristics with the Second Life environment but with complex goals) and has paid attention to linguistic practices, drawing on NLS and Gee's conception of discourses. However, her own interests do not lie in drawing fundamental distinctions between oral and written channels, deploying terms and methods from linguistics and literacy studies in an analytical separation. Justifying this with attention to the manifold dimensions of Gee's (1996) notions of discourses, she here follows in an influential trend to investigate the language of new communications through stress on qualities of dialogicality, informality, etc., led by Baron (1998). ${ }^{2}$

However, for those who practise virtual ethnography with particular attention to literacy practices, it seems to me that there is an opening then to make a distinct delineation of practice for a virtual literacy ethnography, applying diverse interpretive methods and reflexive understandings to the meaning-making practices of a virtual community, particularly attending to the practices of authoring and reading written, multi-modal texts. Sources of project data include: wiki postings (including images captured in-world to record events); forum postings; in-world sensor measurements (of how many people are in-world and where, every minute); chat logs of near-synchronous dialogues and instant messages; and field notes. A number of tools of discourse analysis (taking this term in its broadest sense; see Gillen \& Petersen, 2005) are then available.

\section{Analysing diverse literacy practices of the Schome Park project}

\section{In-world communication}

In order to investigate the students' use of written language in the project at a relatively large scale, I conducted a corpus linguistic analysis of a large, randomised sample of the students' turns in chat logs (mostly near-synchronous with a few instant messages) collected by staff during a 4-week period (of phase 1). These included dyadic chat, tutorials, workshops, meetings, more social encounters, and so on. The students' turns only were extracted and analysed using WordSmith 4 (Scott, 2004). A frequency list of words was created. This was then compared with a 4-million reference corpus, the BNC Baby (a cut-down version of the British National Corpus). The aim of this was to find out what lexical items featured particularly strongly in-world, in comparison with a large sample of language across a wide variety of genres, including newspaper articles, correspondence and everyday conversation by adults. Significant findings were as follows:

- Students' turns were characterised by considerable interrogation and inquiry, with a preponderance of question words such as how and what in comparison with their occurrence in language overall.

- The students are spending considerable energies in dealing with positioning in space and time with words such as time, here, there, now, etc. Functioning in a virtual world entails dynamic processes of orientation that involve cognitive processes and imagination required to function effectively in a virtual environment. Think and because appear far more frequently than in the reference corpus.

- Even a simple lexical analysis at this level is indicative of positive relationship building and collaborative activities - it is perhaps astonishing that in the frequency list yes is high but not no. Haha and LOL indicate shared humour. Help and thanks are indicative of a situation where assistance can be asked for and given and appear 
significantly often. Indeed politeness is prevalent with thanks and please appearing more often than in the reference corpus.

- A few genre-specific terms - such as schomer, $R L$ and $I M$ feature very highly, indicating a shared level of familiarity with these as basic terms in a social group sharing a discourse. However there do not appear so many of them as to suggest a level of intimidating impenetrability for newcomers.

- Thing, things, make and stuff indicate activities around the construction of 'objects' and 'scripts'. These words appear often in the frequency list and in comparison with language overall. The use of simple terms in complex and abstract domains of communication has been noted elsewhere (Swales, 2001).

- Meeting and library feature more often than they do in the overall language corpus, which is not unremarkable given that the reference corpus is adult and contains a considerable amount of text in formal genres.

To give the opportunity for more dense and small-scale analysis, Table 1 presented one specific chat log extract, of which I can attempt a purposeful and necessarily limited discourse analysis (Gillen \& Petersen, 2005). Thus here I draw attention to features of the exchange of particular relevance to investigating issues as outlined above.

As already mentioned the extract was selected partly because it is particularly comprehensible to me several months later as encapsulating a memorable event and therefore lending itself to a situated approach within an ethnographic stance as opposed to, for example, a Conversation Analysis textual analysis in which inferences must be drawn from the text alone (Ten Have, 1999). This extract is relatively structurally simple in comparison with many chat log extracts of similar length in that there are two dialogues in sequence. The dialogue between baso and myself between Turn 1 and Turn 32 contains one point of obvious difficulty in terms of the attainment of intersubjectivity, probably owing to the constraint of the channel in being unable to reflect any temporal overlap: at Turn 9 I ask baso for a copy of a logo (a 'texture' in-world); baso responds at Turn 10 'i didn't make it'. However I seem to have taken this denial at least possibly in connection with the 'transporter', despite knowledge of baso's claim in Line 7, so I explain that the sound effect associated with the object has caused me to identify it as baso's creation (as I remember him to have used it before). Baso seems to recognise the direction of the conversation as being ambiguously balanced with his contributions of 12 and then 13 (an emoticon sometimes glossed as 'tongue in cheek') but at 14 selects as a topic salient to both interactants, the popular culture origins of the sound effect, making a joke at Line 15 I still find delightful. At Turn 16 however I respond to his Turn 14 and so it is not until Turn 19 that I communicate appreciation of his play with the cliché ' $\mathrm{x}$ is so last year' in this environment of 21 st-century technologies and creativity, against the time shifting of science fiction references. Baso's levels of witty communication and instruction are differentially tempered to my capacities of understanding; for example at Line 17 his use of the word 'wear' refers to a choice of simple menu options available in connection with the object, which he correctly guesses I will understand if directed so explicitly, even though I am using the 'teleporter' to move, almost instantly, from one spot in the virtual world to another, as opposed to clothing myself in it. Baso has given me a 'teleporter' I have succeeded in using 'without quite understanding what was going on' as I noted contemporaneously (with understatement). My level of understanding of the programming and scripting of the object and its functioning is limited to my analogy with the 'transporter' in the TV programme 'Star Trek'; baso is willing to communicate 
about it at this popular culture level, although on other occasions with different interactants his dialogues about it will have a higher technical content. The movement was made far more gratifying than it could be otherwise, with the scripted additions of sound effects, slight delay and personalised commentary (at Lines 52 and 54) than it would have been if baso had designed it in a less complex form.

At Turns 34, 35 and 37 Animus attempts to engage baso; as he wants to interact with the scripted object named SPbTP (I assume to stand for 'Schome Park beta teleporter) but baso responds somewhat indirectly through using the abbreviation 'afk' (away from keyboard) possibly as a politeness strategy to mitigate a potentially face-threatening act (Brown \& Levinson, 1987).

The field notes confirm my memory of personal delight at several aspects of this interaction. I was frequently hugely impressed by students' technical abilities and the imagination with which they deployed their ideas. As Joseph (2007) has observed of a more established project using Teen Second Life, students work creatively with the unique affordances of the environment, flourishing as their teachers abandon claims to necessarily superior knowledge and expertise and focus instead on facilitating processes of knowledge exchange and constructive interactional strategies.

\section{Forum}

Returning to Figure 2, it can be seen that, as part of the everyday activity of the Schome Park project Trixxiee has proposed the idea of a Schome Park dictionary, a kind of glossary. From the outset this is designed to be possibly the source of genuinely useful information (to newcomers for example) but also to function as a space for in-group humour. Trixxiee has worked carefully on the format of her dictionary, reflecting knowledge of appropriate generic conventions. Every headword is distinguished by emphasis, followed by an indication of its grammatical status and then a definition. One entry has related words, almost as the lemmas of a lexicographer, in brackets; another, also in similar style, gently caricatured perhaps, has a cross-reference. Trixxiee's work here is on the boundary of Schome Park activity, not directly related to in-world activity. It is, to me, a fascinating, yet not untypical, instance of a new playful genre taking advantage of the affordances and constraints of the domains of Schome Park. The forum is the most appropriate communicative domain for making such a proposal, being less ephemeral than a suggestion made in-world; yet the suggestion is immediately inserted into the community's discussions. Trixxiee is here, a 'cognitive bricoleur ... [one of] the opportunistic assemblers of functional systems composed of internal and external structures' (Hutchins, 1995, p. 172). The external structure she uses so effectively here is the forum, in part through her internalised sense of the structure of a dictionary.

\section{Wiki}

Figure 3 as already mentioned shows the dynamically produced wiki that Trixxiee and Marsbar9 began. The wiki is a relatively persistent document in comparison with a forum posting, and although most wiki pages of the project were authored by one or two persons, with perhaps some additions by others, it is a channel that leads itself well to collaborative authoring. This page is publicly available for viewing, one of 828 such content pages (16 July 2008). A full analysis would include attention to its multimodality (including colour, reduced here) but here I focus on this page as a collaborative authoring activity. In a 'textual ethnography' (Papen, 2007; Swales, 1998) I first 
investigate the history of the development of the page; second, check my interpretive response to this against comparative pages and, third, consider the content of the page in more detail.

First then the 'history' tab at the top of the page was opened to display an automatically recorded account of who has made changes to which section and when. It has elaborate functionality so that if, say, someone with moderating responsibilities has any concerns about a particular new element of text, or formatting decision, then they can compare versions and work out exactly what somebody has done and how. I expect it to be relatively rare that anyone would click onto the 'history' tab of any page. A total of 114 edits to the dictionary were made by 15 participants: 13 students and two staff; a high level of collaboration. Patterns of contribution were diverse. The mean number of edits was 7.4 ( $S D$ 10.12); even more varied was the range of time period over which people worked, the mean being a spread of 33.8 days between first and last edit ( $S D$ 61.20) and the maximum 203.

Despite this evidence of highly motivated engagement, from my experience of the project and knowledge of its now vast resources I had not expected previous accessing of one of these automatically generated pages (4,793 on 16 July 2008) to occur unless someone had a very strong proprietorial sense or, in their role of moderator, had something brought to their attention perhaps by someone else, as a matter of concern. However, Figure 4 shows an extract of one of the history pages relating to the construction of the 'Schome Park dictionary' on 23 June (captured 17 April 2008). The entries relating to the activities for 'Numerius schomer' for example have been recorded wholly automatically. However it is clear that many other entries have had comments appended. These are wholly 'backstage' to the public face of the project.

I was astounded to find that several participants had annotated the automatic record in order to enhance the quality of information available to anyone who did wish to trace the changes. When some have improved formatting or in some small way improved others' entries, they have chosen to explain this to some degree. Such a practice may possibly be drawn from the collaborative editing of Wikipedia that enables conflicts and consensuses alike to be traceable. Myers (2007) has argued that the mass media diatribes against Wikipedia as not necessarily 'accurate' are missing the point of its usefulness; that its particular innovatory value as a reference work lies in its preservation of the traces of its dialogic disputation of contested realities.

\footnotetext{
- (cur) (last) $\bigcirc \bigcirc 21.26 .23$ June 2007

- (cur) (last) $\bigcirc \bigcirc 21: 11,23$ June 2007

- (cur) (last) $\bigcirc \bigcirc 2108,23$ June 2007

- (cur) (last) $\bigcirc \bigcirc 20.58 .23$ June 2007

- (cur) (last) $\bigcirc \bigcirc 20.55 .23$ June 2007

- (cur) (last) $\bigcirc \bigcirc 20.54,23$ June 2007

- (cur) (last) $\bigcirc \bigcirc 20.54,23$ June 2007

- (cur) (last) $\bigcirc \bigcirc 20.53 .23$ June 2007

- (cur) (last) $\bigcirc \bigcirc$ 17:45. 23 June 2007

- (cur) (last) $\bigcirc \bigcirc$ 17:14, 23 June 2007

- (cur) (last) $\bigcirc \bigcirc$ 17:13. 23 June 2007

- (cur) (last) $\bigcirc \bigcirc$ 17:03. 23 June 2007

- (cur) (last) $\bigcirc \bigcirc 14$ 30. 23 June 2007

- (cur) (last) $\bigcirc \bigcirc 14$ 09. 23 June 2007

- (cur) (last) $\bigcirc \bigcirc$ 14 01, 23 June 2007

- (cur) (last) $\bigcirc \bigcirc$ 14.01, 23 June 2007

- (cur) (last) $\bigcirc \bigcirc 14$ 00. 23 June 2007
}

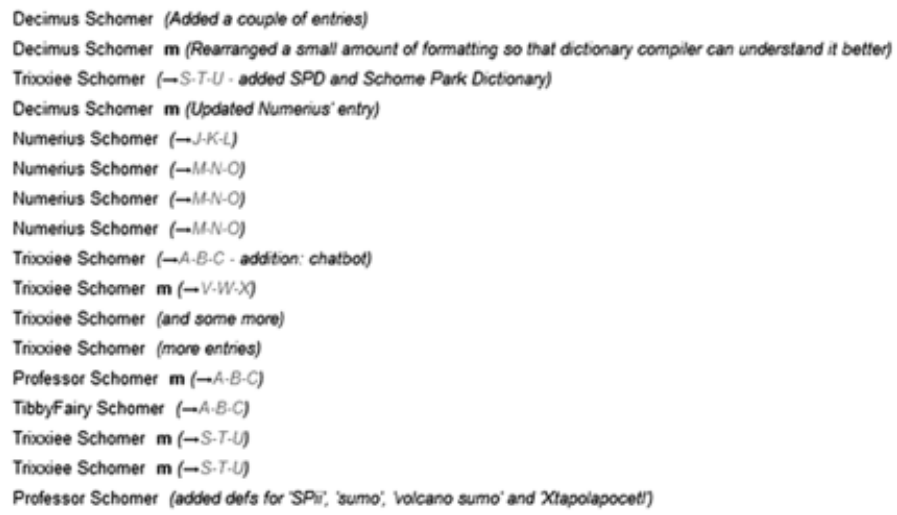

Figure 4. An excerpt from a wiki 'history' page, captured 21 April 2008. 
In order to check my intuition that this finely detailed attention to the collaborating editing process was exceptional, I carried out an analysis of every 50th wiki page. (Because the Schome wiki both pre-existed and continued after the Schome Park project, if the 50th page did not include any student participation between February 2007 and May 2008 then I made use of the next following page that did). This analysis confirmed my intuition that one or two changes at most are common and annotations rare except where accounted for by one Schomer who systematically went through the wiki at one stage 'tidying up' and often briefly explaining her actions.

I now return to consider aspects of the design and content of the dictionary wiki page, as shown in Figure 3. The page has a clear header, an initial description that would be accessible to all (i.e. whether seeing this page for the first time, or more familiar with it) and a brief sentence proclaiming its collaborative authorship through the means of welcoming more contributions. The second paragraph relates to the constantly developing convergence of technologies in the project and requires some knowledge of (Teen) Second Life to understand. The references to in-world and scripts indicate that there is an endeavour to make this into an accessible resource that one can view through one's avatar (i.e. rather than also having to open a web page); apparently this (ambitious) endeavour has met with partial success. However, again, this is clearly part of a collaborative activity with an implied invitation to join in if your motivation and skills are appropriate.

The contents box makes use of the hypermedia functionality or multiple routes of navigation possible on the World Wide Web; you can use this 'window' to quickly find the word you seek, or alternatively close it if you wish to browse down the whole list. The dictionary entries would probably rarely actually be helpful to new entrants to the project and I would suggest that the evidence of the forum thread initiation confirms that they were not designed with this as a true priority. AUP is the 'acceptable use policy' that is drawn to the attention of all newcomers so actually the entry is more a comment on its status (somewhat tongue in cheek) than a 'definition'. Similarly the other entries shown here feature in-group humour, with only chatbot beginning with an actual definition. The dictionary then is part of the Schome Community's discourse; as Lankshear and Knobel (2006, pp. 71-72) write, drawing on work by Gee:

literacies are always about much more, and involve much more, than just the production of texts. They are (also) contexts or pretexts for enacting and refining memberships of Discourses that include such dimensions as feeding back, providing support, sharing knowledge and expertise, explaining rules, sharing jokes ... enacting an affinity.

The dictionary 'project' seems to me a superb exemplar of this.

\section{Conclusions}

This paper can only have given a glimpse of the huge variety of activities and events that occurred in the Schome Park project. The project's web sites and machinimas available on YouTube at the time of writing provide more multi-modal yet possibly ephemeral evidence of these than this paper can. (See www.schome.ac.uk for sites and links to other 
channels.) In this paper I have set out a new synthesis of methods, an approach I term virtual literacy ethnography, to investigate the literacy practices of the project.

Evidence presented and discussed in this paper combats the 'consistently negative representation of young people's new-media language' (Thurlow, 2007, p. 214). Participating in Schome Park is a hugely literate activity. New literacy practices demand attention to all features of a text, moving beyond the linguistic to a semiotic disposition (Kress, 2005). People involved operate often simultaneously with a multiplicity of semiotic resources that have to be deployed in combinations that are patterned in ways to make sense to fellow interactants. And as Jones (2004, p. 326) observes:

If there is any kind of truth to the notion of 'convergence', it is not to be found in the packaging together of technologies into single devices; rather it is to be found in the ongoing proliferation of communication media and tools.

In the complexity of the communicative tools and the relations between them, literacy practices involve cultural knowledge, the employment of artefacts and representations of the world. They are thus precisely in Hutchins' (1995, p. 168) terms part of a 'cognitive ecology in which the various representational technologies constitute one another's functional environments'. In-world chat, environmental print, the wiki, forum, etc. are not best understood then as separate domains but as opportunities for and shapers of interactions by purposeful designers and communicators of the virtual community. Besides the new complexity of channels and resources, evidently there is a new intricacy to the choreography of collaborative authoring and feedback in the cycles of text production and reception that come together so rapidly as to be near-simultaneous: 'the roles of readers and writers overlap' (Merchant, 2007, p. 122). Finally, creativity is as present in the transformations of more traditional genres as it is in the forming of the new.

\section{Notes}

1. Second Life and Teen Second Life are trademarks of Linden Lab, a commercial software organisation based in San Francisco.

2. Gee himself is careful to attend to distinctions between channels, including not to conflate oral and written, and to identify the skills and competences appropriate to each (e.g. Gee, 2003). But, of course, this must depend upon researchers' questions and interests.

\section{References}

Anderson, P. (2007). What is Web 2.0? Ideas, technologies and implications for education. JISC Technology and Standards Watch. Retrieved 17 April 2008, from http://www.jisc.ac.uk/media/documents/techwatch/ tsw0701b.pdf

Anderson-Levitt, K. (2006). Ethnography. In J. Green, G. Camilli \& P. Elmore (Eds.), Handbook of complementary methods in education research. (pp. 279-295). Mahwah, NJ: American Educational Research Association/Lawrence Erlbaum Associates.

Barab, S.A., Kling, R. \& Gray, J.H. (2004). Introduction. In S. Barab, R. Kling \& J.H. Gray (Eds.), Designing for virtual communities in the service of learning. (pp. 3-5). Cambridge: Cambridge University Press.

Baron, N. (1998). Letters by phone or speech by other means: The linguistics of email. Language and Communication, 18, 133-170.

Barton, D. (2007). Literacy: An introduction to the ecology of written language. (2nd edn). Oxford: Blackwell. 
Barton, D. \& Hamilton, M. (1998). Local literacies: Reading and writing in one community. London: Routledge.

Brown, P. \& Levinson, S. (1987). Politeness: Some universals in language usage. Cambridge: Cambridge University Press.

Carter, D. (2005). Living in virtual communities: An ethnography of human relationships in cyberspace. Information, Communication and Society, 8(2), 148-167.

Crowe, N. \& Bradford, S. (2006). 'Hanging out in runescape': Identity, work and leisure in the virtual playground. Children's Geographies, 4(3), 331-346.

Frankel, M. \& Siang, S. (1999). Ethical and legal aspects of human subjects research on the Internet (Workshop report). Washington, DC: American Association for the Advancement of Science. Retrieved 17 April 2008 from http://www.aaas.org/spp/sfrl/projects/intres/report.pdf

Gee, J.P. (1996). Social linguistics and literacies: Ideology in discourses. (2nd edn). London: Taylor and Francis.

Gee, J.P. (2003). What video games have to teach us about literacy and learning. New York: Palgrave Macmillan.

Gillen, J. \& Petersen, A. (2005). Discourse analysis. In B. Somekh \& C. Lewin (Eds.), Research methods in the social sciences. (pp. 146-153). Thousand Oaks, CA: Sage Publications.

Goffman, E. (1959). The presentation of self in everyday life. New York: Doubleday.

Guest, T. (2007). Second lives: A journey through virtual worlds. London: Hutchinson.

Heath, S.B. (1983). Ways with words. London: Cambridge University Press.

Hine, C. (Ed.) (2000). Virtual ethnography. London: Sage.

Hutchins, E. (1995). Cognition in the wild. Cambridge, MA: MIT Press.

Jones, S. (2004). Conclusion: Contexting the network. In P. Howard \& S. Jones (Eds.), Society online: The Internet in context. (pp. 325-334). London: Sage.

Joseph, B. (2007). Global Kids, Inc.'s best practices in using virtual worlds for education. Second Life Education Workshop 2007 Part of the Second Life Community Convention Chicago (pp. 12-19). Retrieved 28 May 2008 from http://www.simteach.com/slccedu07proceedings.pdf

Kress, G. (2005). Communication now and in the future. Paper for the English 21 curriculum consultation project. London: QCA. Retrieved 6 April 2008 from http://www.qca.org.uk/libraryAssets/media/12292_ commun_now_and_in_the_future.pdf

Lankshear, C. \& Knobel, M. (2006). New literacies: Everyday practices and classroom learning. (2nd edn). Maidenhead: Open University Press.

Merchant, G. (2007). Writing in the future in the digital age. Literacy, 41(3), 118-128.

Myers, G. (2007). Be bold: Technology, interaction and the construction of facts in Wikipedia. Paper presented at the annual meeting of the British Association of Applied Linguistics, Edinburgh, 6-8 September.

Papen, U. (2007). Literacy and globalization: Reading and writing in times of social and cultural change. London: Routledge.

Sacks, H., Schegloff, E. \& Jefferson, G. (1974). A simplest systematics for the organisation of turn-taking for conversation. Language, 50, 696-735.

Scott, M. (2004). WordSmith tools. Oxford: Oxford University Press.

Sheehy, K., Ferguson, R. \& Clough, G. (2009). Learning in the panopticon: Ethical and social issues in building a virtual educational environment. International Journal of Social Sciences, 2(2), 89-96.

Squire, K. (2006). From content to context: Videogames as designed experience. Educational Researcher, 35(8), 19-29.

Steinkuehler, C. (2006). Massively multiplayer online video gaming as participation in a discourse. Mind, Culture and Activity, 13(1), 38-52.

Steinkuehler, C. (2007). Massively multiplayer online gaming as a constellation of literacy practices. E-Learning, 4(3), 297-318.

Street, B. (1984). Literacy in theory and practice. Cambridge: Cambridge University Press.

Swales, J. (1998). Other floors, other voices: A textography of a small university building. Mahwah, NJ: Lawrence Erlbaum Associates.

Swales, J. (2001). Metatalk in American academic talk: The cases of point and thing. Journal of English Linguistics, 29(1), 34-54.

Ten Have, P. (1999). Doing conversational analysis: A practical guide. London: Sage.

Thomas, A. (2007). Youth online: Identity and literacy in the digital age. New York: Peter Lang.

Thurlow, C. (2007). Fabricating youth: New-media discourse and the technologization of young people. In S. Johnson \& A. Ensslin (Eds.), Language in the media. (pp. 213-233). London: Continuum. 
Tusting, K. (2008). Ecologies of new literacies: Implications for education. In A. Creese, P. Martin \& N. Hornberger (Eds.), Encyclopedia of language and education: Ecology of language. (2nd edn, Vol. 9, pp. 317-329). Dordrecht: Springer.

Received 21 April 2008; revised version received 31 July 2008.

Address for correspondence: Dr Julia Gillen, Literacy Research Centre, Lancaster University, LA1 4YT, UK. Email: j.gillen@lancaster.ac.uk 